\title{
Constructing a framework of user experience for museum based on gamification and service design
}

\author{
Shunli Liu ${ }^{1}$ and Muhammad Zaffwan Idris²,a \\ ${ }^{1}$ Universiti Pendidikan Sultan Idris, 35900 Tanjong Malim, Perak, Malaysia \\ ${ }^{2}$ Universiti Pendidikan Sultan Idris, 35900 Tanjong Malim, Perak, Malaysia
}

\begin{abstract}
Museum plays an integral part in modern society. For nearly four decades, museums around the world have experienced a shift in their focus from "object" to "people", and attempted to enhance the visitors' experience through various means. In the context of museum open to the public, however, the museum has not become a place frequently visited by people in China. This paper focuses on exploring a method of constructing a model to achieve a desirable user experience (UX) in museum through adapting the role of Gamification and Service Design. The purpose of this study is to inspire potential visitors, specifically the young generation, to have their own motivations to constantly visiting the museum.
\end{abstract}

\section{Introduction}

In the history of development urbanization, the museum has been thought of as a key factor in effectively expanding the space for cultural sharing, enhancing the cultivation of populace, and shaping humanistic spirit [1]. In the column Front Line of the journal "Art \& Design", the expert demonstrated that the largest core driving force of a country's culture is the museum, which is the top of the cultural pyramid [2]. However, research have shown that both virtual and physical museum tend to focus on the representation of information [3], they cannot stimulate potential visitors to be motivated enough to visit the museum continuously.

Essentially, assortment of artefacts is not the only mission of the museum, the issue of exhibition, education, interpretation and commitment to community has received considerable critical attention in the twentieth century [4]. Over the past century, museums have shown an increased interest in attracting visitors, which is a shift of service concept from the exhibits to the audience, and put more emphasis on the relationship between the museum and the public. People can be seen as both rational and emotional, and often pursue the User Experience (UX) of fantasies, feelings, and fun [5]. It can be seen from a recent study involving a questionnaire that 'entertainment' accounts for the highest proportion $(80 \%)$ of the audience's motivation to visit the museum [6].

In order to achieve better museum UX, identifying users' different experience needs is prerequisite. Next, museum needs to investigate what services should museum provides to users throughout the process of PreVisit, During-Visit, and Post-Visit. Fortunately, the using of interdisciplinary design strategies such as Gamification and Service Design is expected to help to achieve the aims. Hence, this paper focuses on exploring a method of constructing a model to achieve a desirable museum UX through the role of Gamification and Service Design.

\section{Museum}

In recent years, the interest in redefining the function of museum has increased. For example, in 2007 the International Council of Museums (ICOM) emphasized in the latest museum definition that museum functions include education, study, and enjoyment. Historically from definitions proposed by ICOM, education, study, and enjoyment are the most cited in the purpose of the museum since the 1960s. Moreover, the educational function is becoming more and more important today. The mission of the new era museum is that not only concerned about the collection, but also concerned about how to use the collection; not only concerned about the arts, but also the people [7] .

In the context of museum open to the public, one may presume that the museum has become a place that regularly visit by people, but in China, this is not the case. In 2015, China Youth Daily survey showed that only $17.3 \%$ of respondents frequented the museum and $61.1 \%$ of the respondents occasionally visited, due to lack of affinity for the museum, inconvenient access to information, and weakness of interactive visit [8]. Compared with the average frequency of visiting museums in developed countries that is three to five times per year, every citizen in China enters the museum about every two years on average [9]. Museums should

\footnotetext{
${ }^{*}$ Corresponding author: ${ }^{a}$ zaffwan@,fskik.upsi.edu.my

${ }^{1}$ Shunli Liu also serves as a lecturer at the Art \& Culture College of Tianjin University of Sport.
} 
learn to interact with their visitors specifically the young generation who are not passionate about ancient art such as paintings $[3,10]$. Today, museums are often overlooked by young people [11]. To a certain extent, the participation of the young generation could determines the museum's future audience [3].

In order to attract more young people to participate in museums, a study has been conducted and proved the complementary relationship between physical museum and virtual museum [12]. It can be seen that the physical museum is mainly related to the 'During-Visit', and the virtual museum is mostly related to the 'Pre-Visit' as well as 'Post-Visit'. However, there are some deficiencies in previous studies. First of all, there has been less discussion about the issue on how the museum systematically connects virtual museums and physical museums throughout 'Pre-Visit', 'During-Visit', and 'Post-Visit'. In addition, previous studies ignored the different needs from UX. It may be feasible that a new method to increase the audience's experience is needed. In particularly through gathering insight into the psychology of young people, categorizing museum audiences based on their intrinsic motivation and identifying users' different experience needs.

\section{User experience (UX)}

For the definition of UX, scholars highly recommend the definition that proposed by Nielsen, a well-known UX designer and researcher. The definition is as follow: “'User Experience' encompasses all aspects of the enduser's interaction with the company, its service, and its products." [13-14]. There are other opinions believes that the UX is a feeling of strong excitement [15]. In other words, feelings beyond expectations can be called user experience.

Consumer or visitor should be able to obtain three different levels as shown in figure 1. The progressive relationship from low to high for: Functionality, Usability and Pleasure. (1) Functionality: no function, no use. What the product be used for, as well as the context or environment in which it will be used must be understood; (2) Usability: users expect the product easy to use; (3) Pleasure: according to the theory 'hierarchy of human needs', higher level needs always follow the prior satisfaction has been achieved, that is why after the Usability is satisfied, the user is inevitable to pursue more, such as emotional experience.

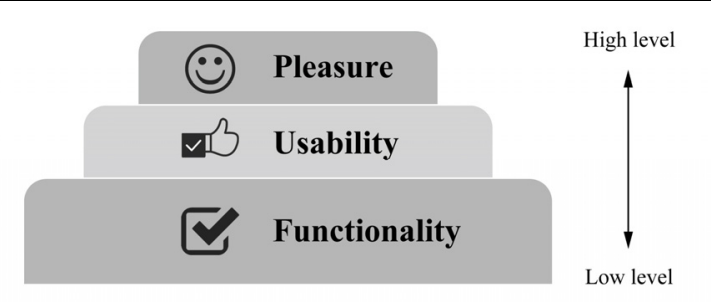

Figure 1. The hierarchy of consumer needs follows Maslow's theory

\section{Gamification}

\subsection{Game}

Maroney defined the game as: "a game is a form of play with goals and structure." [16] The author defined the game by four shared traits: a goal, rules, a feedback system, and voluntary participation [17]. Gaming elements increase the visitor engagement because of the 'Edutainment', which is a solution that combines education and entertainment to enhance learning experiences [18]. Gamers can achieve more in online worlds than they can in real life. They can have stronger social relationships in games than they can have in real life, they get better feedback and feel more rewarded in games than they do in real life. The broken reality needs to use the game to repair [17]. Players do believe that they are capable of changing virtual worlds and not the real world. Hence, we have to start making the real world work more like a game [19].

\subsection{Understanding Gamification}

The term Gamification was defined as follows: "Gamification is the use of elements of game design in non-game contexts." [20] This definition helps distinguish 'Gamification' from 'Game'. The term 'nongame contexts' tends to mean that the purpose of using game elements is to help accomplish other things. The figure 2 presents more detailed explanation of the Gamification definition mentioned above [21].

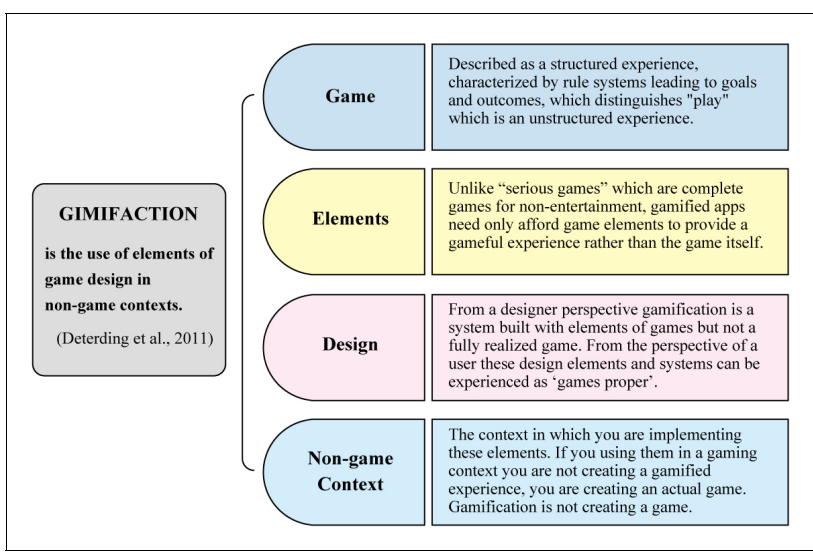

Figure 2. Detailed explanation of the Gamification definition

In recent years, there has been an increasing amount of literature on Gamification. Deterding et al. said: "Origins Gamification as a term originated in the digital media industry. The first documented use dates back to 2008." [20] The authors further pointed out the use of the term Gamification was widely adopted by some industry participants and conferences in the second half of 2010. Additionally, although Gamification originated in the digital media industry, it does not need to focus only on digital form since the distinction between digital and non-digital artefacts is increasingly blurred.

As a non-game environment, the museum is expected to introduce Gamification concepts to enhance the UX. In order to attract new target groups, especially young people, Gamification is one of the ways to solve the problem of museum audience reduction [11]. Specifically, the same study provided new insights into 
another potential problem: "How can potential visitors be motivated to visit the museum continuously and how can knowledge of the artwork be transferred?" The Gamification is a better scientific solution since it is a way to increase user engagement by adding game mechanism.

\section{Service Design}

Like any product, services need to be designed. As early as 2005, the International Council of Societies of Industrial Design (ICSID) included services in the definition of design [22]. In 2006, with the arrival of The First Nordic Conference on Service Design and Service Innovation, the Service Design began to be concerned [23]. In the 1990s, the traditional service industry was growing and design still focused on physical and tangible production. During this decade, the main task of the Service Design was to let the idea of 'design could and should work on services' be accepted by society [24].

\subsection{Definition of Service Design}

The term Service Design was defined as: "The process of planning and organizing people, infrastructure, communication and material components of a service, with the goal of improving the service's quality, the interactions between a provider and its customers, and the customers' experiences." [25] In the article entitled Building A Service Design Explanation, the authors hold the point that Service Design is the design of how a service delivers an experience to their customers over time [26].

\subsection{Time concept of Service Design}

According to the time, the touchpoints in Service Design can be divided into three stages: 'Pre-Service', 'During Service', and 'Post-Service' [22]. The figure 3 shows these three stages concisely: (1) Pre-Service: The contact before customers got service such as advertising, website, promotion, the main purpose is marketing; (2) During Service: Each touchpoint in the service process, such as the services provided by the airport (registration procedures, security procedures, shopping, rest, internet, catering, smoking, prayer rooms, children's play area); (3) Post-Service: Customer contact after leaving the service such as maintenance and management, aftersales service, customer loyalty management. Further, Service design enables users to enjoy aesthetics, escape from reality, enjoy entertainment or be educated.

Public places such as museums and airports will increasingly be transformed into complexes of services, which are closely related to the visitors' lifestyle. In the column Front Line of the journal “Art \& Design”, Chen Nan, the deputy director of Visual Communication Design Department, Academy of Fine Arts, Tsinghua University, mentioned: "the purpose of people going to the museum not necessarily for the exhibition, but a way of life on weekends." [2]. Consistent with the concept of Service Design, museums also have the concept of time flow. The Service Design can help enhance the museum experience through the organization of traditional and virtual during 'Pre-Visit', 'During-Visit', and 'PostVisit'.

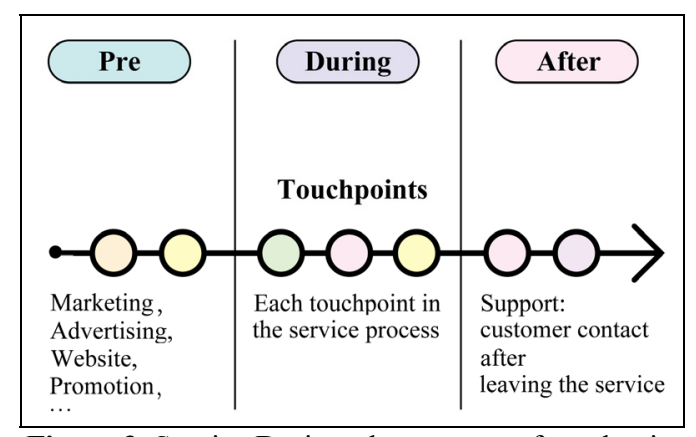

Figure 3. Service Design: three stages of touchpoints

\section{Application of Gamification and Service Design in improving the UX of museum}

\subsection{Application of meaningful Gamification}

Incorporating Gamification concept into the process of enhancing UX in museums is not a simple use of game elements because most Gamification that offering rewards is only suitable for the short-term purpose instead of the long-term change.

\subsubsection{Meaningful Gamification based on intrinsic motivations}

It is undeniable that rewards can help players to enter the system. For example, the use of badges and points can guide players and lead people to engage with a system. Over time, however, the role of rewards should be gradually reduced and replaced by ongoing meaningful engagement since intrinsic motivations are more motivated than external motivation [27]. The concept of meaningful Gamification was introduced by Nicholson to achieve the long-term change [28], which emphasizes intrinsic or internalized motivations for people's engagement in activities. The author pointed out: "removing the scoring elements from a Gamification context encourages a focus on the integration of play". That is to say, meaningful Gamification encourages a deeper integration of game mechanisms into non-game contexts.

\subsubsection{Player needs based on SDT}

The Self-Determination Theory (SDT) proposed by Deci and Ryan shows how to make systems that help users find their own reasons for engagement through constructing intrinsic motivation [27].

Using Gamification thinking, players in game can be identified into four types: achievers, socializers, explorers, and attackers [29]. This theory can be applied to the classification of museum audience's visit motivation. By analyzing types of player, Nicholson 
connected the player types to the three basic needs in SDT [27], and the conclusion is shown in the figure 4: (1) Using Gamification systems, Socializers tend to meet and engage with others, they are interested in the Relatedness concept; (2) Try to break the boundaries of the Gamification system, Explorers desire to participate in broadness, they value the concept of Play and pay special attention to the Autonomy element; (3) Achievers are looking for a feeling of accomplishment, they highly value the Competence (Mastery) element; (4) Attackers expect competition and conquest, and value the Mastery element of SDT.

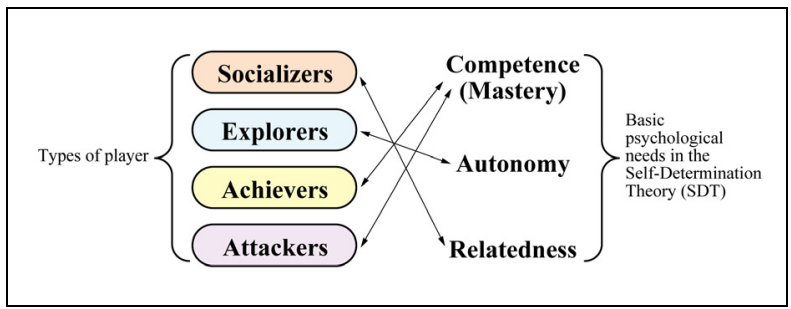

Figure 4. Framework of gamer psychology

\subsection{Application of Service Design}

According to the principle of touchpoints in Service Design, the touchpoints of service design can be divided into three stages: 'Pre-Service', 'During-Service', and 'Post-Service'. In the same vein, the audience experience of the museum can be divided into 'Pre-Visit', 'DuringVisit', and 'Post-Visit' [30]. In general, the Pre-Visiting stage is mainly information and ticket service; the During Visiting stage is mainly based on deep excursions and knowledge services, including watching, listening and touching; the Post-Visiting stage is mainly for sharing exchanges, souvenir buying, and entertainment services.

Although most of the studies focus on 'During-Visit' of the museum, existing research has recognized the critical role played by 'Pre-Visit' and 'Post-Visit'. After researching several groups of people, the researchers found $57 \%$ of people visiting museum websites before and after they visit the physical museum [31]. Therefore, the introduction of the concept of Service Design will help the museum enhance its UX throughout the entire process of 'Pre-Visit', 'During-Visit', and 'Post-Visit'.

\subsection{Exploring a model to achieve a desirable museum UX}

When exploring a model for museum UX, the designer can classify the audience based on the above player types to find out their respective motivations to go to the museum. The process of classifying the audience must be combined with the various services the museum should provide. After that, in conjunction with the concept of 'Pre-Visit', 'During-Visit', and 'Post-Visit', Service Design concepts helping to enhance museum UX can be explored. This process connects virtual museums with physical museums, inspiring potential visitors motivated to constantly visit the museum. To clarify and propose relationships among the concepts, the framework for this study was established and presented in figure 5 .

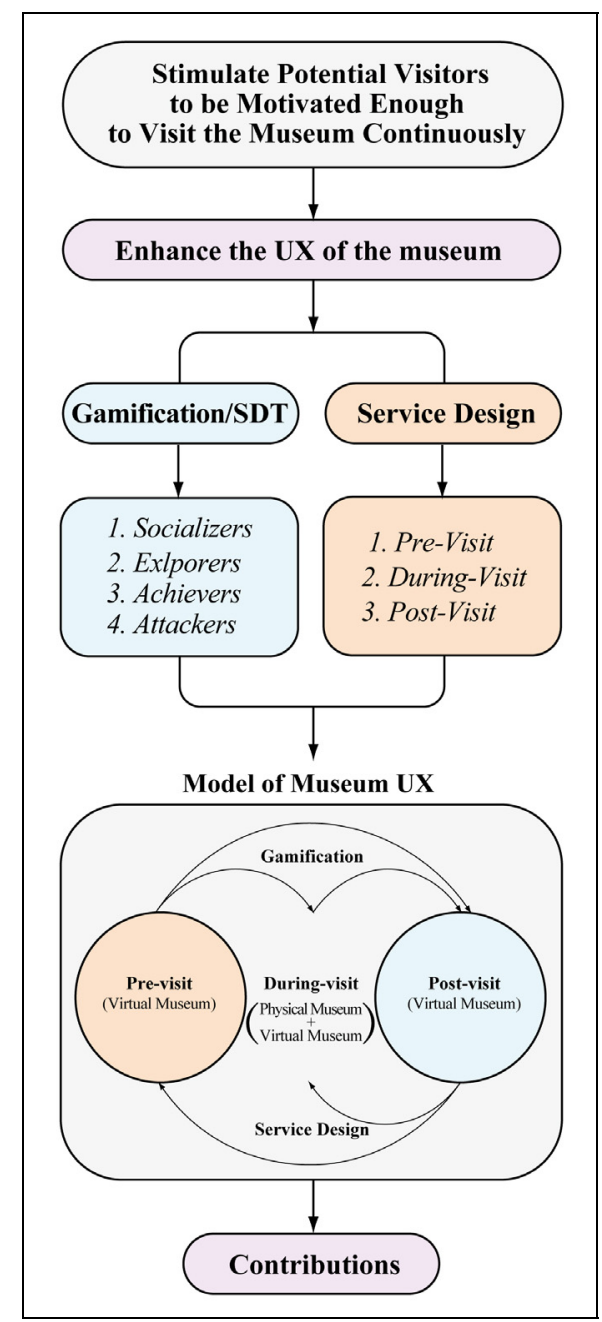

Figure 5. The framework of research

\section{Conclusion}

In general, this paper focuses on exploring a method of constructing a model to achieve a desirable museum UX through the application of Gamification and Service Design. As a cross-disposing study, this work use different perspectives to help the museum to better understand its audiences so as meeting the experience demand by different types of users. Through this research, it is expected that the participation of the young generation will be highly achievable for the museum's future main audience.

\section{References}

1. P. Jian, S. Q. Li. Social Education and the Development of the Museum. In S. H. M. Secretariat of CAMOC-CSM (Ed.), Variation of City Memory: Proceeding of CAMOC-CSM (20132014) (pp. 618-622). Guang'an, Sichuan; Xiamen, Fuijian: Shanghai Jiao Tong University Press. (2014) 
2. Z. Zhou. Discussion on Cultural Products of Museums. Art \& Design, (4), 46-51(2016)

3. F. Izzo. Museum Customer Experience and Virtual Reality: H.BOSCH Exhibition Case Study. Modern Economy, 8(4), 531-536 (2017)

4. E. P. Alexander, M. Alexander, J. Decker. Museums in Motion: An Introduction to the History and Functions of Museums. Rowman \& Littlefield. (2017)

5. M. B. Holbrook, E. C. Hirschman. The Experiential Aspects of Consumption: Consumer Fantasies, Feelings, and Fun. Journal of Consumer Research. (1982)

6. S. Y. Li. The Development of Museum APPs and its Solutions. Journal of Huizhou University, 37(4) (2017)

7. P. W. Jordan. Designing Pleasurable Products An Introduction to the New Human Factors. Boca Raton, Florida: CRC Press, Taylor \& Francis Group. (2002)

8. J. Liu, F. L. Liu. Public Service Design of Internet+ Museum Based on Role Cognition: Taking the Palace Museum as an Example. Art \& Design, (11), 118-119 (2017)

9. J. McGonigal. Reality is Broken: Why Games Make Us Better and How They Can Change the World. New York: The Penguin Press. (2011)

10. W. Hürst, B. de Boer, W. Florijn, X. J. Tan. Creating New Museum Experiences for Virtual Reality. In Multimedia \& Expo Workshops (ICMEW), 2016 IEEE International Conference (pp. 1-6). IEEE. (2016)

11. A. Döpker, T. Brockmann, S.Stieglitz. Use Cases for Gamification in Virtual Museums. Informatik 2013, Informatik Angepasst an Mensch, Organisation Und Umwelt: Tagung Vom 16. - 20. September 2013 in Koblenz; 43rd Meeting of the German Informatics Society, (September 2013), 2308-2321 (2013)

12. P. F. Marty. Museum Websites and Museum Visitors: Before and After the Museum Visit. Museum Management and Curatorship, 22(4), 337360(2007)

13. L. Miller. The Practitioner's Guide to User Experience Design: Top Practitioners Share Lessons Learned on the Journey from Beginner to Expert. UK: Hachette. (2015)

14. D. Norman, J. Nielsen. The Definition of User Experience (UX) (n.d.). Retrieved December 1, 2017 , from https://www.nngroup.com/articles/definition-userexperience/

15. H. Y. Zhou. Zhou Hongyi's Own Statement: My Internet Methodology. Beijing: China CITIC Press. (2014)

16. K. Maroney. My Entire Waking Life. The Games Journal, 5(2001). Retrieved from
http://www.thegamesjournal.com/articles/MyEntire WakingLife.shtml

17. J. McGonigal. Reality is Broken: Why Games Make Us Better and How They Can Change the World. New York: The Penguin Press. (2011)

18. L. Van Der Lans, E. L. Ansems, V.-J. Khan. BrainChain App: A Fully Crowdsourced Design Process for Museums. Eindhoven University of Technology, (May). (2016)

19. J. McGonigal. Gaming Can Make A Better World. (2010). Retrieved from https://www.ted.com/talks/jane_mcgonigal_gaming _can_make_a_better_world\#t-737987

20. S. Deterding, R. Khaled, L. Nacke, D. Dixon. Gamification: Toward a Definition. CHI 2011 Gamification Workshop Proceedings, (January 2011), 12-15(2011)

21. J. Charalambous. S Health Redesign. (n.d.). Retrieved January 9, 2018, from https://jasoncharalambous.myportfolio.com/shealth-redesign

22. Z. Qin. To Enhance Service Experience Through Service Touchpoints Design. Package \& Design, (3), 103-105 (2014)

23. S. Holmlid. Participative, Co-Operative, Emancipatory: From Participatory Design to Service Design. In First Nordic Conference on Service Design and Service Innovation (p. 14) (2009)

24. D. Sangiorgi. Building Up A Framework for Service Design Research. In 8th European Academy Of Design Conference 1st 2nd 3rd April 2009 (pp. 415420). Aberdeen, Scotland: The Robert Gordon University. (2009). Retrieved from http://ead09.org.uk/Papers/037.pdf

25. M. Steen, M. Manschot, N. De. Koning. Benefits of Co-Design in Service Design Projects. International Journal of Design, 5(2), 53-61 (2011). Retrieved from uuid:eefaaa3c-cc7d-408e-9e00-883c6f2ccb03

26. S. Sandoval, O. Sortland. Building A Service Design Explanation. (2013). Retrieved from http://odasortland.com/service-design-explanation/

27. S. Nicholson. A RECIPE for Meaningful Gamification. (T. Reiners \& L. C. Wood, Eds.), Gamification in Education and Business. New York. (2015)

28. S. Nicholson. A User-Centered Theoretical Framework for Meaningful Gamification. In Games+ Learning+ Society (Vol. 8, pp. 223-230). Madison, WI. (2012)

29. R. A. Bartle. Designing Virtual Worlds. US: New Riders. (2004)

30. J. Liu, F. L. Liu, Public Service Design of Internet+ Museum Based on Role Cognition: Taking the Palace Museum as an Example. Art \& Design, (11), 118-119(2017)

31. V. Kravchyna, S. K. Hastings. Informational Value of Museum Web Sites. First Monday, 7(2) (2002) 